\title{
O DIREITO JUDICIÁRIO LUSITANO - OS ASSENTOS DA CASA DA SUPLICAÇ̃̃O
}

\author{
THE LUSITAN JUDICIARY LAW - SUPPLICATION HOUSE STATEMENTS
}

\section{Maria Cristina da Silva Carmignani*}

\begin{abstract}
Resumo:
O tema tem como enfoque principal retratar a função de interpretar as leis, de forma autêntica, da Casa da Suplicação em Lisboa, por meio de assentos normativos. Será demonstrado que essa função interpretativa da lei conferida à Casa da Suplicação na verdade implicava em verdadeira atividade legislativa, introduzindo profundas modificações no Direito Privado Português no período de um século entre a Lei da Boa Razão até a promulgação do Código Civil português.

Palavras-chave: Interpretação autêntica. Lei. Casa da Suplicação. Assentos normativos. Direito Privado Português. Lei da Boa Razão.
\end{abstract}

\begin{abstract}
:
The main goal of this paper is to present the "authentic" interpretation function of the laws, by the Supplication House in Lisbon, by means of normative statements. It will be demonstrated that this interpretative function by the Supplication House implied true legislative activity, that introduced deep changes in the Portuguese Private Law along centuries since the enactment of the "Boa Razão Law" until the enactment of the Portuguese Civil Code.
\end{abstract}

Keywords: Authentic interpretation. Law. The Supplication House. Normative statements. Portuguese Private Law. Boa Razão Law.

1. O Direito Judiciário Lusitano

1.1. Os arestos

No período de formação do Estado português, ${ }^{1}$ o costume era a fonte primordial do direito, havendo costumes gerais e jurisprudenciais.

Mario Júlio de Almeida Costa explica que,

nessa época, utilizava-se o conceito de costume num sentido amplo ou residual: abrange todas as fontes de direito tradicionais que não tenham caráter legislativo. Denominação genérica em que se incluíam sentenças da Cúria Régia, depois designadas costumes da Corte, de juízes municipais e de juízes arbitrais (juízes "alvidros" ou

Professora Doutora de História do Direito da Faculdade de Direito da Universidade de São Paulo. A respeito da formação do Estado Português ver, por todos, CAETANO, Marcello. História do direito português. 3. ed. Lisboa: Editorial Verbo, 1992. p. 177 e ss. 
"alvedrios"), isto é, nomeados por acordo entre as partes, cujas decisões se tornavam precedentes vinculativos. ${ }^{2}$

A essas decisões judiciais que adquiriam força vinculante, dava-se o nome de façanhas, termo este que foi muito usado em Castela. ${ }^{3}$

Nesse mesmo sentido, João Mendes de Almeida Júnior informa que, mesmo antes das Ordenações do Reino, já na Lei das Partidas (Liv. III, ley XIV), uma decisão judicial, quando notável - que denominavam de façanha - ou se referisse a algum caso omisso, tornava-se um precedente, sendo aplicado em outros casos semelhantes: ${ }^{4}$

Otrosy dezimos, que non deue valer ningum juyzio que fuesse dado por fazãnas de otro; fueras ende, si tomassem aquella fazãna de juyzio que el Rey ouisse dado. Ca entonces bien pueden julgar por ella; porque la del Rey há fuerça, e deue valer como ley, em aquel pleyto sobre que es dado, e em los otros que fuerem semejantes.

O mesmo autor traz em sua obra passagens de diversos estudiosos reinóis a respeito do sentido da expressão façanhas, atestando a utilização do direito judiciário como fonte criadora do direito, de forma vinculante: ${ }^{5}$

Em uma dissertação sôbre o verdadeiro sentido desta palavra - façanhas, empregada na cit. Ordenação, estudo de JOSÉ ANASTÁCIO DE FIGUEIREDO, inserto no tomo I das Memórias da Academia Real de Ciências de Lisboa, aí está notado que DUARTE NUNES DO LIÃO, na Parte Primeira da Crônica dos Reis de Portugal, afirma que façanha "é um juízo sôbre algum feito notável e duvidoso, que por autoridade de quem o fêz e dos que o aprovaram e louvaram, ficou dêle um direito introduzido para se imitar e seguir como lei, quando outra vez acontecesse". CABELO, aliás não contestando a definição de DUARTE NUNES, amplia o sentido da palavra, afirmando que façanha, "é o mesmo que opinião altercada". Outra definição dá D. RODRIGO DA CUNHA, na História Eclesiástica de Lisboa, a qual definição, em fundo, é a mesma de DUARTE NUNES; pois façanha, diz êle, "é um tal e tão generoso feito que, assim pela estranheza e valor com que foi obrado, como pela autoridade da pessoa que obrou e daqueles que o louvaram e celebraram, mereceu e alcançou um prudencial

2 COSTA, Mario Júlio de Almeida. História do direito português. 2. ed. 2. Reimpr. Coimbra: Almedina, 1996. p. 190 e ss.

3 Cf. COSTA, Mario Júlio de Almeida. História do direito português ... cit., p. 190 e ss.

4 ALMEIDA JÚNIOR, João Mendes de. Direito judiciário brasileiro. 5. ed. São Paulo: Freitas Bastos, 1960. p. 442 e ss.

5 ALMEIDA JÚNIOR, João Mendes de. Direito judiciário brasileiro ... cit., p. 442 e ss. 
juízo de ter tido e havido por lei onde concorressem iguais ou semelhantes circunstâncias.

Após o séc. XVI a expressão façanha cai em desuso, sucedendo-lhe as expressões casos julgados e arestos, assim chamadas as decisões judiciais, não suscetíveis de reforma, proferidas em forma de julgamento definitivo, pelos tribunais superiores. ${ }^{6}$

Esses arestos ou casos julgados eram inicialmente proferidos pelos Reis, Magistrados ou por Árbitros, sendo que só aquele proferido pelo Monarca é que tinha força de lei, referente sempre a direitos e interesses de particulares. ${ }^{7}$

Cabe lembrar, ademais, que como na Idade Média não havia a separação dos poderes, era comum que os juízes também declarassem o direito, criando novas regras que, após, eram aplicadas em casos análogos ou idênticos.

No entanto, a partir do reinado de Afonso III, as leis gerais passam a ter supremacia sobre os costumes, como reforço da autoridade régia - influência do direito justinianeu - deixando de ser uma fonte esporádica e passando a ser modo corrente de criação do direito. ${ }^{8}$

Com as Ordenações do Reino, que deu novos contornos à organização judiciária de Portugal, os arestos ou casos julgados passaram a ser classificados de acordo com o tribunal que proferia a decisão, podendo ser arestos da Casa da Suplicação de Lisboa, da Casa do Porto e das relações.

Os arestos proferidos pela Casa da Suplicação possuíam mais autoridade que os demais e, “quando tomados diante d' El Rey e mandando-o êle guardar em casos semelhantes", tornavam-se precedentes que vinculavam, representando uma atividade jurisdicional de criação do direito.

Não há que se confundir, no entanto, os arestos com os assentos proferidos pela Casa da Suplicação de Lisboa. Estes últimos, na verdade, refletiam uma efetiva atividade legislativa do judiciário no sentido de proferir autêntica interpretação da lei, nos casos de divergência, não se referindo à decisão de casos particulares, como cuidavam os arestos.

João Mendes Júnior muito propriamente diferencia os arestos dos assentos, informando que "Os Assentos são atos do Poder Judiciário, não resolvem litígios hic et nunc, isto é, são determinações sobre a inteligência das leis, quando na execução delas ocorrem dúvidas manifestadas por julgamentos divergentes: os arestos são casos julgados entre certas e determinadas partes litigantes". Continua, ainda, afirmando que "Os Assentos associam o Poder judiciário ao Poder Legislativo, ao passo que os arestos mantêm o Poder

Cf. ALMEIDA JÚNIOR, João Mendes de. Direito judiciário brasileiro ... cit., p. 443.

ALMEIDA JÚNIOR, João Mendes de. Direito judiciário brasileiro ... cit., p. 445-446.

8 Cf. COSTA, Mario Júlio de Almeida. História do direito português ... cit., p. 254 e ss. 
Judiciário na esfera de suas atribuições: os Assentos são leis, ao passo que os arestos são simples exemplos que podem ser seguidos ou não em casos semelhantes e que não obrigam senão às próprias partes que intervieram no feito". 9

As Ordenações referiam-se, ainda, dentre as fontes do direito nacional, ao lado da lei e dos costumes, aos estilos da Corte que, segundo os doutrinadores seriam a jurisprudência uniforme e constante dos tribunais superiores e que seriam imperativos, a partir do séc. XVII, se proferidos pela Casa da Suplicação. ${ }^{10}$

\subsection{Os Assentos da Casa da Suplicação}

Em Portugal, inicialmente, a interpretação autêntica da lei era faculdade atribuída ao monarca que, muitas vezes, presidia às reuniões dos tribunais superiores decidindo as questões que eventualmente surgissem.

Em virtude da complexidade cada vez maior da administração, o rei deixa de presidir essas sessões dos tribunais, dando origem ao alvará de D. Manuel I, que confere essas funções à Casa da Suplicação. ${ }^{11}$

Referido alvará, de 1518, conferia aos desembargadores da Casa da Suplicação ${ }^{12}$ a resolução de dúvidas de interpretação que surgissem a respeito de algum preceito e a dita solução ficaria registrada no Livro dos Assentos, tendo força vinculante para casos futuros idênticos, surgindo então esses assentos como jurisprudência obrigatória.

Candido Mendes de Almeida, ${ }^{13}$ no prefácio ao Auxiliar Jurídico (apêndice às Ordenações Filipinas) - que contêm a compilação de todos os Assentos da Casa da Suplicação, desde 1603 até a sua extinção no Brasil - informa que estes tinhão por fim fixar a verdadeira intelligência da Lei; e tomados na Meza Grande daquella Caza ou Relação tinhão, e ainda tem, força de lei.

A solução adotada no alvará de 1518, conferindo à Casa da Suplicação essa atribuição, foi repetida nas demais Ordenações reinóis (Manuelinas e Filipinas):

por iniciativa de D. Manuel I, foram os poderes do Rei,
nesse domínio, como que transferidos para o próprio
tribunal supremo do Reino (Casa da Suplicação), mantendo
o monarca, apenas, como da sua competência reservada, a
interpretação daquelas dúvidas sobre cujo esclarecimento

ALMEIDA JÚNIOR, João Mendes de. Direito judiciário brasileiro ... cit., p. 444.

10 Cf. COSTA, Mario Júlio de Almeida. História do direito português ... cit., p. 300-301, nota 1 e 2.

11 Cf. COSTA, Mario Júlio de Almeida. História do direito português ... cit., p. 296-297.

12 A Casa da Suplicação era o tribunal superior do Reino, que inicialmente acompanhava a Corte e depois se fixou em Lisboa.

13 ALMEIDA, Cândido Mendes de. Auxiliar jurídico: apêndice às ordenações filipinas. Rio de Janeiro: Instituto Philomathico, 1869. v. 1, p. 6. 
a Casa da Suplicação se mantivesse hesitante, e que o respectivo Regedor, por isso mesmo, entendesse devessem ser levadas à apreciação régia. ${ }^{14}$

Nesse sentido, dispunha as Ordenações Manuelinas, no Livro V, título LVIII, parágrafo $1^{\circ}$ :

quando os Desembargadores que forem no despacho de alguu feitos, todos ou alguu delles teurem algua duvida em algua nossa Ordenaçam do entendimento della, vam com a dita duvida ao Regedor, o qual na Mesa grande com os Desembargadores que lhe bem parecer determinará, e segundo o que hi for determinado se poerá a sentença. E se dita Mesa forem isso mesmo em duvida, que ao Regedor pareça que he bem de No-lo fazer, pêra Nós loguo deterinarmos, No-lo fará saber, pêra Nós nisso provermos. E os que em outra maneira interpretarem Nossas Ordenações, ou derem sentenças em algum feito, tendo algum delles duvida no entendimento da dita Ordenaçam, sem hirem ao Regedor como dito he, serm suspensos atee Nossa Mercê. E a determinaçam que sobre o entendimento da dita Ordenaçam se tomar, mandará o Regedor escrever no livrinho para depois nom viir em duvida.

Desta forma, quando surgiam dúvidas aos desembargadores daquele tribunal superior, em virtude do entendimento de algum preceito, seriam levadas ao Regedor, que convocaria os demais desembargadores e, juntos, fixavam a interpretação mais adequada, 15 podendo inclusive, conforme o caso, submeter a dúvida à resolução do monarca, se subsistissem dificuldades interpretativas. ${ }^{16}$

As soluções fixadas eram registradas no Livro dos Assentos, passando a ter força vinculante para casos futuros, ou seja, tornavam-se jurisprudência obrigatória.

Essas mesmas disposições foram repetidas nas Ordenações Filipinas, no Livro I, título $\mathrm{V}$, parágrafo $5^{\mathrm{o}}$ :

E havemos por bem, que quando os Desembargadores, que forem no despacho de algum feito, todos ou algum deles tiverem alguma dúvida em alguma nossa Ordenação do entendimento dela, vão com a dúvida ao Regedor; o qual na Mesa grande com os Desembargadores, que lhe bem parecer, a determinará e, segundo o que aí for determinado, se porá a sentença. E a determinação, que sobre o entendimento da

\footnotetext{
14 Cf. CRUZ, Guilherme Braga da. O direito subsidiário na história do direito português. Revista Portuguesa de História, Coimbra, v. 14, 1975. (Separata) p. 283, 1975.

15 COSTA, Mario Júlio de Almeida. História do direito português ... cit., p. 297.

16 In: COSTA, Mario Júlio de Almeida. História do direito português ... cit., p. 297.
} 
dita Ordenação se tomar, mandará o Regedor escrever no livro da Relação, para depois não vir em dúvida. E se na dita Mesa forem isso mesmo em dúvida, que ao Regedor pareça, que é bem de no-lo fazer saber, para Nós logo determinarmos, no-lo fará saber, para nisso provermos, E os que em outra maneira interpretarem nossas Ordenações, ou derem sentença em algum feito, tendo algum deles dúvida no entendimento da Ordenação, sem ir ao Regedor, será suspenso até nossa mercê.

Verifica-se que a Casa da Suplicação funcionava como um órgão legislativo, proferindo solução que passava a ter força normativa e que, diferentemente das façanhas, eram proferidas em sessão especial e não na resolução de um caso particular, fixando a inteligência das leis.

Tinham assim os assentos por objetivo uniformizar o entendimento a respeito da interpretação in abstrato de uma regra constante das Ordenações, e não eliminar divergência de julgados.

Em 1582, foi deslocada a Casa do Cível - que funcionava com uma segunda instância em Lisboa - para o Porto, criando a Casa da Relação do Porto, como tribunal de segunda e última instância, exceto em matéria cível, nas causas em que o valor ultrapassasse um determinado montante..$^{17}$

A partir de então também esse tribunal, apesar de ser órgão inferior à Casa da Suplicação, passou a proferir assentos interpretativos normativos, embora não tivesse competência legal para tanto - o mesmo fazendo as outras Relações posteriormente criadas - o que foi coibido mais tarde, pela denominada Lei da Boa Razão, de 18 de agosto de 1769 .

\subsection{A Lei da Boa Razão e os Assentos}

A Lei da Boa Razão - assim chamada em virtude das inúmeras passagens em seu texto em que se refere à Boa Razão - reconhece a força vinculante dos assentos, assim dispondo no parágrafo $4^{\mathrm{o}}$ :

Mando... que os assentos já estabelecidos, que tenho determinado que sejam publicados e os que se estabelecerem daqui em diante sobre as interpretações das leis, constituam leis inalteráveis para sempre se observarem como tais, debaixo das penas estabelecidas.

17 Cf. COSTA, Mario Júlio de Almeida. História do direito português ... cit., p. 298-299. A respeito da organização judiciária em Portugal, ver por todos CAETANO, Marcello. História do direito português ... cit., p. 482 e ss. 
A mesma lei, no parágrafo $8^{\circ}$, regula a competência para proferir esses assentos normativos, reconhecendo autoridade exclusiva ao Tribunal Supremo do Reino - a Casa da Suplicação - únicos dotados de poder vinculante, e que poderiam se dedicar à autêntica interpretação das leis.

A Lei da Boa Razão vem pôr fim aos abusos cometidos pelos tribunais inferiores, que se arvoravam em proferir assentos de cunho normativo, determinando que os assentos proferidos por esses órgãos só teriam força vinculante, se confirmados fossem pela Casa da Suplicação, nos seguintes termos:

\begin{abstract}
Attendendo a referida Ord., Liv. 1 tit. 5, pr. 5 não foi estabelecida para as Relações do Porto, Bahia, Rio de Janeiro, e Índia, mas sim, e tão somente para o Supremo Senado da Casa de Supplicação; e attendendo a ser manifesta a differença, que há entre as ditas Relações subalternas, e a Suprema Relação de Minha Corte; a qual antes pela Pessoal Presidência dos Senhores Reys Meus Predecessores; e depois pela proximidade do Throno, e facilidade de recorrer a elle; pela authoridade de seu Regedor, e pela maior experiência de seus doutos, e provectos Ministros, não só mereceo a justa confiança, que della fizarão sempre os ditos Senhores Reis Meus Predecessores (...) para dita interpretação das Leis. Mas também constitue ao mesmo tempo nos Assentos, que nella se tomão sobre esta importante matéria toda quanta certeza pode caber na providencia hummana para tranqüilizar a Minha Real Consciência; e a Justiça dos Litigantes sobre os seus legítimos direitos (...).
\end{abstract}

De acordo ainda com essa lei, os assentos poderiam ser proferidos em três situações distintas, que já eram contempladas nas Ordenações: ${ }^{18}$

a) por efeito de dúvidas de interpretação levantadas pelos desembargadores;

b) por efeito de glosas do Chanceler, decorrentes de dúvidas levantadas no momento de selar as sentenças do tribunal, quanto à sua legalidade, por lhe parecerem contra texto expresso das Ordenações ou do direito romano. ${ }^{19}$

c) para definição de estilos ${ }^{20}$ antigos da Casa da Suplicação, esta última

18 Cf. CRUZ, Guilherme Braga da. O direito subsidiário na história do direito português ... cit., p. 284 e ss, nota de rodapé n. 109.

19 Cf. CRUZ, Guilherme Braga da. O direito subsidiário na história do direito português ... cit., p. 284 e ss, nota de rodapé n. 109.

20 Consoante ensina Corrêa Telles, chama-se Estylo o uso acerca do modo de praticar o que as Leis mandão. Segundo o mesmo autor, para que tivesse força de lei era preciso que o estilo fosse da Casa da Suplicação, e que fossem confirmados por Assentos. TELLES, José Homem Corrêa. Comentário crítico à Lei da Boa Razão. In: ALMEIDA, Cândido Mendes de. Auxiliar jurídico: apêndice às Ordenações Filipinas. Lisboa: Fundação Calouste Gulbenkian, 1985. v. 2. (Facsimile da edição de 1869). p. 449. 
modalidade inserida pela Carta Régia de 7 de junho de 1605.

Além das três formas acima descritas, a Lei da Boa Razão veio acrescentar, no entanto, uma quarta modalidade: assentos por efeito de dissidência entre os advogados litigantes quanto ao entendimento da lei aplicável, in verbis:

Parágrafo $6^{\circ}$.- Item: Mando que não só quando algum dos Juízes da Causa entrar em dúvida sobre intelligencia das Leis, ou dos estilos, a deva propor ao Regedor para se proceder a decisão della por Assento na forma das sobreditas Ord., e Reformação; mas que também se observe igualmente o mesmo, quando entre os Advogados dos Litigantes se agitar a mesma duvida; pertencendo o do Author, que a Lei se deva entender de hum modo; e pertendendo o do Reo, que se deva entender de outro modo. E nestes casos terá o Juiz Relator a obrigação de levar os Autos á relação, e de propor ao Regedor a sobredita controvérsia dos Advogados, para sobre ella se proceder na forma das ditas Ordenações, e Reformação dellas, a Assento, que firme a genuína intelligencia da Lei antes que se julgue o direito das partes.

Ressalte-se que nesse caso se os advogados agissem com deslealdade, com o fito de procrastinar o feito, a lei estabelecia, no parágrafo $7^{\circ}$, severas sanções; inicialmente multa de $50 \$ 000$ réis para as despesas da Relação e seis meses de suspensão; na segunda vez, privação do exercício profissional; na terceira vez - caso outra pessoa assinasse clandestinamente as suas alegações - pena de degredo por 5 (cinco) anos em Angola.

Por fim, foi criada uma quinta modalidade, por meio de um Assento de 16 de fevereiro de 1786, que se daria em razão de ordem da Rainha, transmitida por aviso do Secretário de Estado. ${ }^{21}$

Em quaisquer das formas de assentos contemplados pela legislação pombalina, conferia-se autoridade única e exclusiva à Casa da Suplicação, Tribunal Supremo do Reino, para proferi-los com cunho normativo, bem como para transformar os estilos em assentos. ${ }^{22}$

Continuaram os assentos da Casa da Suplicação a terem por objetivo dirimir dúvidas a respeito da interpretação da lei, não existindo a previsão de qualquer

${ }_{21}$ Cf. informa CRUZ, Guilherme Braga da. O direito subsidiário ... cit., em nota V, p. 286, referido Assento foi proferido para dirimir questões sobre a transmissão de bens alodiais, vinculados e aprazados.

22 Neste tocante, verifica-se que a Lei da Boa Razão retirou o valor autônomo dos Estilos da Corte, que somente teriam valor vinculante se confirmados por assento proferido pela Casa da Suplicação (cf. CRUZ, Guilherme Braga da. O direito subsidiário ... cit., p. 291. 
modalidade para uniformizar o entendimento dos tribunais a respeito de um determinado assunto, ou seja, para eliminar contradição de julgados.

Todos os assentos eram tomados, em qualquer das suas formas, com o objetivo de eliminar dúvidas de interpretação da lei que surgissem até antes do julgamento da causa, ou em grau de recurso, mas não necessariamente em virtude da existência de outros julgados que fossem contraditórios.

Portanto, a função de interpretar as leis, de forma autêntica, cabia ao Tribunal Superior do Reino, por meio de assentos normativos, exercendo o Tribunal verdadeira atividade legislativa, muitas vezes criando, até mesmo, novas regras.

Esse aspecto é ressaltado por Braga da Cruz, ao analisar a função interpretativa da lei conferida à Casa da Suplicação por meio dos assentos, apontando o seu papel criador e afirmando que, a pretexto de mera interpretação, e utilizando os critérios a esse propósito proclamados pela legislação pombalina, conseguiram os nossos juristas, por vezes, introduzir inovações profundas no direito vigente. ${ }^{23}$

A ação criadora da jurisprudência, por meio dos assentos da Casa da Suplicação, agora fundada na recta ratio e no usus modernus, manteve ainda o seu importante papel de interpretação e integração das lacunas da lei, fixando os novos rumos do Direito Privado português.

Braga da $\mathrm{Cruz}^{24}$ confirma a importância do direito judicial, no período de um século entre a Lei da Boa Razão até a promulgação do Código Civil, como tendo sido de vital importância para o moderno direito português, base para a formação do substrato doutrinário em que aquele Código havia de assentar-se, não apenas dando interpretação diversa daquela anteriormente dada a um preceito das Ordenações, mas divulgando novas doutrinas ou preenchendo as lacunas do ordenamento jurídico.

\section{O Declínio do Direito Judicial e o Positivismo Jurídico}

Não resta dúvida de que, na construção do direito português moderno, até a promulgação de seu Código, foi de vital importância o direito judicial, introduzindo novas regras, atualizando princípios jurídicos, enfim, fixando novos rumos.

No entanto, também em Portugal, na esteira do ideário da separação dos poderes no século XVIII, após a revolução francesa, a vontade do povo passa a expressar a fonte primordial do direito, de forma que a função legislativa torna-se monopólio de

\footnotetext{
23 Cf. CRUZ, Guilherme Braga da. A formação histórica do moderno direito privado português e brasileiro. Revista da Faculdade de Direito, Universidade de São Paulo, São Paulo, v. 50, p. 32-77, jan./dez. 1955. p. 23 e ss., 1954, onde aponta vários exemplos dessa atividade criadora.

24 Cf. CRUZ, Guilherme Braga da. A formação histórica ... cit., p. 21-22.
} 
um poder exclusivamente criado para tal, o poder legislativo, sem que possa haver a ingerência de qualquer outro poder, notadamente o poder judicial. ${ }^{25}$

Essa necessidade em se buscar a unicidade do direito, procurando oferecer o mesmo para todos, resultou dos abusos e excessos cometidos na Idade Média, e em face da complexidade e multiplicidade das regras de direito existentes, imperando o positivismo jurídico. ${ }^{26}$

A partir de então, passa-se à primazia da lei, como fonte única do direito, relegando-se o juiz ao exercício de uma atividade mecânica de aplicação da norma bouche de la loi - compilada em códigos, o que vem corroborado pela técnica adotada pela escola da exegese, que predomina na França de Napoleão.

A moderna democracia considera, assim a "representação popular como expressão da vontade geral... e a maioria legislativa como fonte exclusiva de direito, erigindo ambas em único requisito de validade geral da lei. ${ }^{27}$

No século XIX, no entanto, gradativamente verifica-se a necessidade em se dar maior abertura ao ordenamento jurídico, tendo em vista que a lei não conseguia prever todas as situações da vida, deixando abertas lacunas, que precisavam da atuação do juiz na qualidade de intérprete - para a sua integração.

Novas escolas surgem, dentre as quais a Escola Histórica do Direito, a jurisprudência dos interesses, ambas na Alemanha, que vão relativizando àquele positivismo clássico, resgatando o prestígio da atividade judicial, inserindo o juiz como um descobridor do direito, não mais reduzido a um mero executor, passando a jurisprudência a ocupar novamente um papel importante como fonte do direito. ${ }^{28}$

Não obstante, permaneceu nos países da Europa Continental, a concepção de que a lei é fonte primordial do direito, cabendo a jurisprudência exercer um papel apenas complementar, de interpretação da vontade do legislador e de preenchimento das lacunas do ordenamento.

São Paulo, junho de 2016.

25 HESPANHA, António Manuel Botelho. Panorama histórico da cultura jurídica européia. Mem Martins: Europa-América, 1998. p. 172.

26 A respeito das origens do positivismo jurídico, ver por todos, BOBBIO, Norberto. O positivismo jurídico ... cit.

27 Cf. WIEACKER, Franz. História do direito privado moderno. Tradução de A. M. Botelho Hespanha. Lisboa: Fundação Calouste Gulbenkian, 1967. p. 647.

28 A respeito das várias Escolas, ver por todos BOBBIO, Norberto. O positivismo jurídico ... cit. 


\section{Referências}

ALMEIDA, Cândido Mendes de. Auxiliar jurídico: apêndice às ordenações filipinas. Rio de Janeiro: Instituto Philomathico, 1869. v. 1, p. 6.

ORDENAÇÕES FILIPINAS. Lisboa: Fundação Calouste Gulbenkian. Reprodução “fac-símile” da edição de 1870, feita na Real Imprensa da Universidade de Coimbra.

ORDENAÇÕES MANUELINAS. Lisboa: Fundação Calouste Gulbenkian. Reprodução "facsímile" da edição de 1797, feita na Real Imprensa da Universidade de Coimbra.

\section{Obras}

ALMEIDA JÚNIOR, João Mendes de. Direito judiciário brasileiro. 5. ed. São Paulo: Freitas Bastos, 1960.

BOBBIO, Norberto. O positivismo jurídico: lições de filosofia do direito. São Paulo: Ícone, 1999.

CAETANO, Marcello. História do direito português. 3. ed. Lisboa: Editorial Verbo, 1992.

COSTA, Mario Júlio de Almeida. História do direito português. 2. ed. 2. Reimpr. Coimbra: Almedina, 1996.

HESPANHA, António Manuel Botelho. Panorama histórico da cultura jurídica européia. Mem Martins: Europa-América, 1998.

TELLES, José Homem Corrêa. Comentário crítico à Lei da Boa Razão. In: ALMEIDA, Cândido Mendes de. Auxiliar jurídico: apêndice às Ordenações Filipinas. Lisboa: Fundação Calouste Gulbenkian, 1985. v. 2. (Facsimile da edição de 1869).

WIEACKER, Franz. História do direito privado moderno. Tradução de A. M. Botelho Hespanha. Lisboa: Fundação Calouste Gulbenkian, 1967.

Artigos de publicações periódicas

CRUZ, Guilherme Braga da. O direito subsidiário na história do direito português. Revista Portuguesa de História, Coimbra, v. 14, 1975. (Separata)

CRUZ, Guilherme Braga da. A formação histórica do moderno direito privado português e brasileiro. Revista da Faculdade de Direito da Universidade de São Paulo, São Paulo, v. 50, p. 32-77, jan./ dez. 1955. 
